\section{Co-operative mineralization and protein self-assembly in amelogenesis: silica mineralization and assembly of recombinant amelogenins in vitro}

Fowler CE, Beniash E, Yamakoshi Y, Simmer JP, Margolis HC. Co-operative mineralization and protein self-assembly in amelogenesis: silica mineralization and assembly of recombinant amelogenins in vitro. Eur J Oral Sci 2006; 114 (Suppl. 1): 297-303 (C) Eur J Oral Sci, 2006

\begin{abstract}
An amorphous silica mineralization technique was used to produce inorganic/protein composites to elucidate the structure and mechanism of formation of amelogenin assemblies, which may play an important role in regulating enamel structure during the initial stages of amelogenesis. Full-length recombinant amelogenins from mouse (rM179) and pig (rP172) were investigated along with key degradation products (rM166 and native P148) lacking the hydrophilic C terminus found in parent molecules. The resulting products were examined using transmission electron microscopy and/or small-angle X-ray scattering. Using protein concentrations of $0.1-3 \mathrm{mg} \mathrm{ml}^{-1}$, large monodisperse spheres of remarkably similar mean diameters were observed using rM179 $(124 \pm 4 \mathrm{~nm})$ and rP172 $(126 \pm 7 \mathrm{~nm})$. These spheres also exhibited internal structure', comprising nearly spherical monodisperse particles of $\approx 20 \mathrm{~nm}$ in diameter. In the presence of rM166, P148, and bovine serum albumin (control), large unstructured and randomly shaped particles $(250-1000 \mathrm{~nm})$ were observed. Without added protein, large dense spherical particles of silica (mean $\approx 500 \mathrm{~nm}$ ) lacking internal structure were produced. These findings demonstrate that full-length amelogenins have the ability to form higher-order structures, whereas amelogenins that lack the hydrophilic $\mathrm{C}$ terminus do not. The results also suggest that full-length amelogenin can guide the formation of organized mineralized structures through co-operative interactions between assembling protein and forming mineral.
\end{abstract}

Christabel E. Fowler ${ }^{1}$ Elia Beniash ${ }^{2}$, Yasuo Yamakoshi ${ }^{3}$, James $P$. Simmer $^{3}$, Henry C. Margolis ${ }^{2}$

${ }^{1}$ GlaxoSmith Kline, Weybridge, Surrey, UK: ${ }^{2}$ Department of Biomineralization, The Forsyth Institute, Boston, MA, USA; ${ }^{3}$ University of Michigan Department of Biologic and Materials Science, School of Dentistry, Ann Arbor, MI, USA

H. C. Margolis, Department of Biomineralization, The Forsyth Institute, 140 The Fenway, Boston, MA 02115, USA

Telefax: +1-617-892-8432

E-mail: hmargolis@forsyth.org

Key words: amelogenesis; amelogenin; mineralization; self-assembly; silica

Accepted for publication November 2005
The functional capabilities of the mineralized tissues of the human body are derived largely from their unique structures and compositions. As a result of variations in the distribution of organic matter and inorganic crystals of different sizes, shapes, and organization, these mineralized tissues differ significantly with respect to physical properties (1). Compared with other mineralized tissues (e.g. dentin, cementum, and bone), dental enamel is distinct in that it is composed mostly of mineral ( $>95 \%$ mineral by weight) and contains relatively little organic material (1$2 \%$ lipids and proteins). The mineral component of all these tissues is, however, similar with respect to composition. Enamel mineral is hydroxyapatite-like in nature and contains appreciable quantities of carbonate, sodium, and magnesium. The enamel tissue is also highly and uniquely organized, with long crystals of enamel mineral arranged into parallel rods, which are tightly packed in a species-specific manner. In general, these rods are aligned along the direction of maximum stress, providing enamel with hardness comparable to that of titanium (2).

As in the case of other mineralized tissues, enamel mineral is formed through a process mediated by matrix proteins. It is believed that matrix proteins play a critical role in the control of both the onset of mineralization and the resulting organization of the developing mineral crystals. Thus, tissue ultrastructure is believed to be largely controlled by matrix proteins. Although a number of studies have examined the effects of specific matrix proteins from bones and teeth as initiators (or inhibitors) of mineralization (3), little is known regarding the mechanism by which matrix proteins serve to control mineralized tissue organization.

Amelogenins constitute up to $90 \%$ of the extracellular matrix in developing enamel, and several studies have confirmed that amelogenin is essential for proper enamel mineral formation in vivo (4-7). The largely hydrophobic nature of amelogenin leads to several intriguing physical properties. For example, the solubility of amelogenin is lower in neutral solution than in acidic or basic solutions (8). In a number of previous studies (9-16), amelogenin molecules have also been shown to self-assemble to form nanometre-sized spheres ('nanospheres'). Although very little is known about the precise role of these aggregates in the formation of enamel, it has been suggested that self-assembly of the protein may be important for proper enamel formation. Several recent transgenic studies have shown that alterations in specific regions of amelogenin, 
believed to affect its self-assembly, result in the disruption of proper enamel mineral formation $(17,18)$.

Indeed, a key feature of many biological macromolecules is their ability to self-assemble. The resulting superstructures play major roles in a variety of biological processes, but in particular in the control of nucleation and organized growth of biominerals, such as dental enamel (19). As shown in Fig. 1, although amelogenins are mostly hydrophobic, they possess a hydrophilic C terminus (20). Self-assembly may therefore result from the amphiphilic nature of the protein, a factor that could be of primary importance in directing the enamel mineral growth.

In order to gain insight into their structures, amorphous silica has been used to mineralize organized assemblies of molecules, as in studies on the use of surfactants or synthetic polymers as organic templates for the preparation of porous inorganic materials (21). In addition, a large number of examples exist in the literature where the structural characterization of biological organisms and supramolecular assemblies, such as viruses, has been facilitated through their mineralization using silica (22-26). As amelogenin is rich in polar histidine and glutamine residues, which have previously been shown to act as nucleation sites for the deposition of mineral phases (27), it may be possible to produce an inorganic 'cast' of an amelogenin hierarchical structure, if one exists, through silica mineralization. Such dense structures would possess enhanced electron and X-ray contrast, providing a means by which the degree of organization and lattice parameters could be determined. Thus, the silica mineralization reaction may provide new insights into the formation of organized assemblies of amelogenin, even under non-physiological in vitro conditions, through interactions between the protein surface functionalities and charged polymerizing silica species.

The aim of this investigation was to use the silica mineralization technique to detect and study the ability of amelogenin to form superstructures, in order to obtain insight into the role of specific protein assemblies in the development of the enamel tissue.

\section{rM179* - PLPPHPGSPGYINLSYEVLTPLKWYQSMIR $\underline{\underline{\mathrm{rP172}}}$ - PLPPHPGHPGYINFSYEVLTPLKWYQNMIR QPYPSYGYEPMGGWLHHQIIPVLSQQHPPSH HPYTSYGYEPMGGWLHHQIIPVVSQQTPQSH \\ TLQPHHHLPVVPAQQPVAPQQPMMPVPGHHS ALQPHHHIPMVPAQQPGIPQQPMM PLPGQHS \\ MTPTQHHQPNIPPSAQQPFQ-QPFQPQAIPP MTPTQHHQPNLPLPAQQPFQPQPVQPQPH-- \\ * lacks $\mathrm{N}$-terminal methionine and $\mathrm{PO}_{4}$ \\ ** hydrophilic at pH7.4 - WPATDKTKREEVD $+++-\cdot$ \\ rM166 - same as rM179, but lacking the hydrophilic $C$ terminus $\underline{\mathrm{P} 148}$ - same as rP172, but with $\mathrm{N}$-terminal methionine and $\mathrm{PO}_{4}$ (S-16), and lacking the hydrophilic C terminus}

Fig. 1. Aligned amino acid sequences of recombinant and native amelogenins investigated in the present study.

\section{Material and methods}

\section{Experimental procedures}

A mixture of tetraethoxysilane (TEOS) and aminopropyltriethoxysilane (APTES) (90 and $10 \mathrm{~mol}$ percentage of silica source, respectively; $14.5 \mu \mathrm{l}$ volume) was added to an aqueous solution $(310 \mu \mathrm{l})$ containing a known concentration of amelogenin $\left(100 \mu \mathrm{g} \mathrm{ml}^{-1}\right.$ to $\left.4 \mathrm{mg} \mathrm{ml}^{-1}\right)$. The protein solution was previously prepared and equilibrated at room temperature overnight. On addition of the ethoxysilane mixture, the reaction vessel was agitated to thoroughly mix the components, then left stationary for $3 \mathrm{~d}$. Experiments were repeated at different temperatures and for various initial protein concentrations. The effect of mechanical stirring of the reaction mixture was also investigated. A white precipitate formed after different reaction times, depending on the conditions used. Bovine serum albumin (BSA) was used as a control.

Aminopropyltriethoxysilane was added to the reaction mixture for the following reasons (28):

(i) The amine functionality catalyzes the hydrolysis of the ethoxy groups, resulting in an increased rate of reaction at near-neutral $\mathrm{pH}$. This condition is favorable for the mineralization of biological molecules, which may undergo significant structural changes under extreme $\mathrm{pH}$ conditions.

(ii) Aminopropyltriethoxysilane increases the hydrophilicity of the silica mixture, decreasing phase separation on addition to the protein solution.

(iii) The amine functionality may provide additional favorable interactions between the silica framework and the protein surface.

Following a series of preliminary experiments, a ratio of $90: 10 \mathrm{~mol}$ percent for TEOS:APTES was found to provide optimal interactions between the growing silica framework and the protein surface. By altering this ratio, or by changing the total concentration of silica, the reaction kinetics is disturbed and favorable protein/silica interactions are lost. Altering the molar ratio of TEOS:APTES has the potential to affect a number of reaction parameters, including the rate of hydrolysis of the ethoxysilane groups, the overall degree of silica condensation, and interactions between the amine groups of the silica framework and the protein. A slight $\mathrm{pH}$ increase also occurs with an increased concentration of APTES. Molar ratios of TEOS:APTES of $95: 5$ and $80: 20$ were investigated. When the silica mixture contained $5 \mathrm{~mol}$ percent APTES, the reaction proceeded more slowly, and a precipitate was not evident until day 5. Transmission electron microscopy (TEM) of the product showed amorphous silica particles and dense aggregates. At $20 \mathrm{~mol}$ percent APTES, a precipitate formed within a matter of seconds, and a significant amount of unstructured amorphous silica was again detected by TEM, after just $24 \mathrm{~h}$. Small numbers of particles, similar to those obtained using $10 \mathrm{~mol}$ percent APTES, were also detected in this case. Higher and lower overall silica concentrations resulted in the formation of a significant quantity of unstructured silica, and fewer or no particles possessing internal structure.

\section{Enamel proteins}

Four enamel matrix proteins were investigated, including full-length recombinant proteins from mouse (rM179) and 
from pig (rP172). Again, as illustrated in Fig. 1, the fulllength recombinant amelogenins are mostly hydrophobic in nature, but possess a common 13-amino acid hydrophilic $\mathrm{C}$ terminus. Recombinant rM166 and native P148 were also studied and represent major degradation products of amelogenin found in vivo. Notably, rM166 and P148 lack the 13amino acid hydrophilic tail found in the full-length parent molecules. All of the recombinant proteins lack an N-terminal methionine and a single phosphate group at S-16. P148 also lacks an additional 12 amino acids from the $\mathrm{C}$ terminus and is phosphorylated at S-16. Note that there is significant homology between the mouse and pig sequences, although they are not identical. The recombinant proteins were produced in Escherichia coli, and purified as previously described (29,30). Native P148 was isolated from developing pig enamel and purified according to published procedures (31).

\section{Analyses}

All samples were analyzed using TEM (JEOL1200 EX, operating at $120 \mathrm{keV}$ ). The suspensions resulting from the mineralization reactions were diluted with distilled water, and droplets were air-dried onto carbon-coated 3-mm- diameter copper TEM grids. Particle diameters were measured from TEM printed images. Mean values and standard deviations were based on measurements of 25 particles for each experiment.

Small-angle X-ray scattering analysis was performed on a Bruker (Bruker AXS, Madison, WI, USA) two-dimensional (2D) small-angle diffractometer with a rotating anode X-ray generator and operating at $40 \mathrm{kV}, 1.2 \mathrm{~kW}$, and $30 \mathrm{~mA}$. The sample-detector distance was $604 \mathrm{~mm}$, and the beam diameter was $100 \mu \mathrm{m}$.

\section{Results}

Low-magnification TEM studies of silica/rM179 and silica/rP172 composites $\left(1 \mathrm{mg} \mathrm{ml}^{-1}\right.$ protein) revealed a dense population of large $(\approx 125 \mathrm{~nm}$ in diameter $)$ monodisperse spherical particles (Fig. 2A) of remarkably uniform size (Table 1). Occasionally, coalescence was observed, but the vast majority of the particles were discrete. Transmission electron microscopy observations at higher magnification revealed that all particles
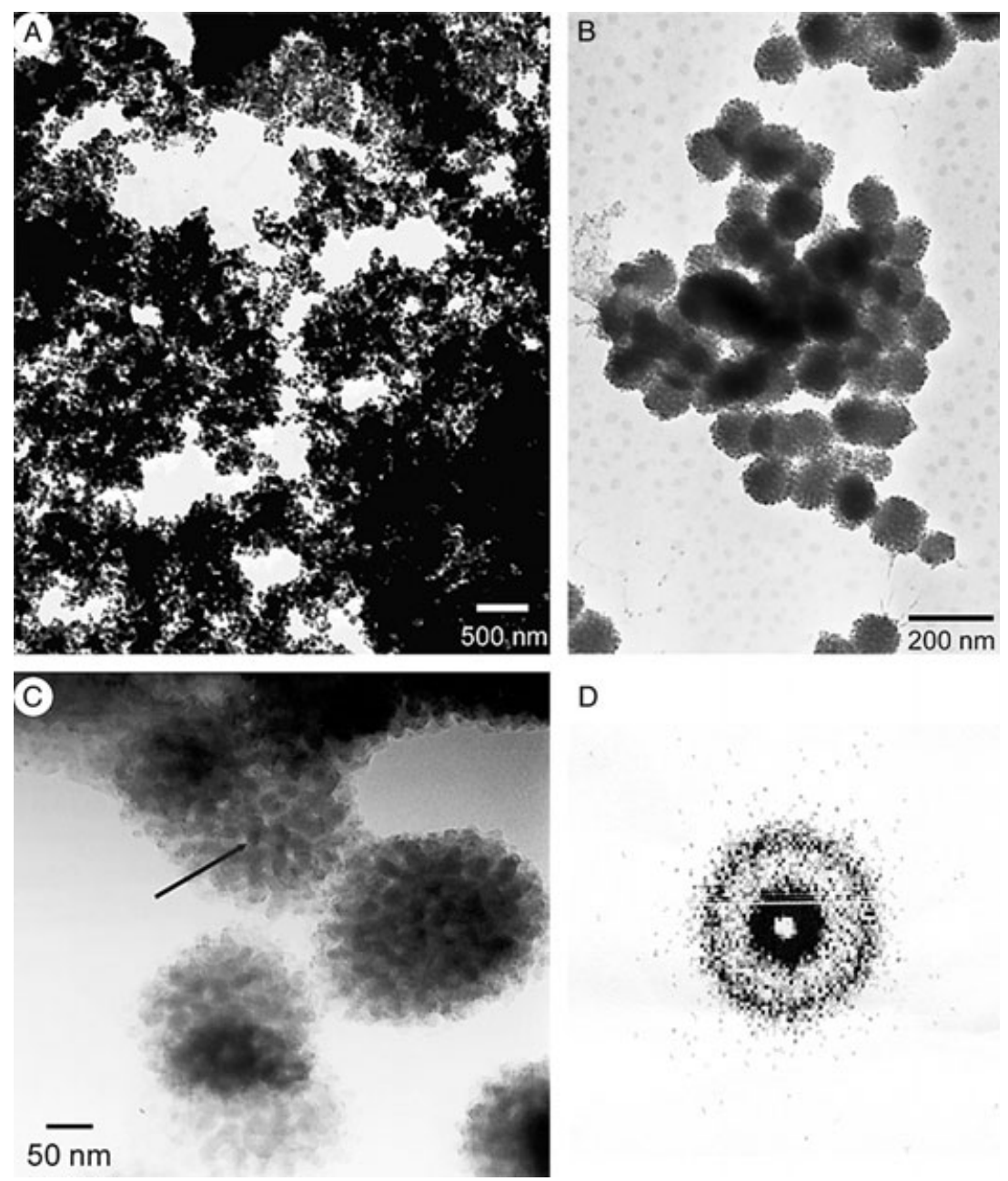

D

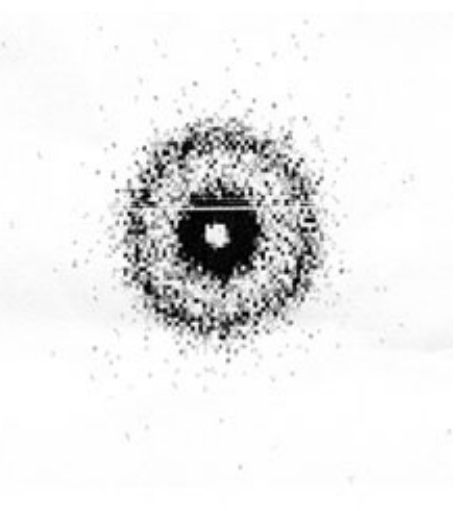

Fig. 2. Unstained transmission electron microscopy (TEM) images of (A) silica/rM179 and (B) silica/rP172 composites using $1 \mathrm{mg} \mathrm{ml} l^{-1}$ protein, at low magnification; (C) silica/rM179 composites using $1 \mathrm{mg} \mathrm{ml}^{-1}$ protein, at high magnification, showing clear evidence of internal structure, comprising smaller spherical monodisperse particles, with diameters of $\approx 20 \mathrm{~nm}$ (arrow); (D) Smallangle X-ray scattering results showing a single broad ring pattern, corresponding to a d-spacing of $21.5 \mathrm{~nm}$. 
Table 1

Mean partide size and standard deviation of silica/amelogenin composites prepared under various conditions*

\begin{tabular}{|c|c|c|c|c|}
\hline \multirow[b]{2}{*}{ Sample } & \multicolumn{2}{|l|}{ rM179 } & \multicolumn{2}{|l|}{ rP172 } \\
\hline & $\begin{array}{l}\text { Mean particle } \\
\text { size }(\mathrm{nm})\end{array}$ & $\begin{array}{l}\mathrm{SD} \\
(\mathrm{nm})\end{array}$ & $\begin{array}{l}\text { Mean particle } \\
\text { size }(\mathrm{nm})\end{array}$ & $\begin{array}{l}\mathrm{SD} \\
(\mathrm{nm})\end{array}$ \\
\hline $100 \mu \mathrm{g} \mathrm{ml}^{-1}$ & 121 & 13 & 132 & 16 \\
\hline $500 \mu \mathrm{g} \mathrm{ml}^{-1}$ & 130 & 15 & 121 & 13 \\
\hline $1 \mathrm{mg} \mathrm{ml}^{-1}$ & 123 & 17 & 134 & 22 \\
\hline $2 \mathrm{mg} \mathrm{ml}^{-1}$ & 127 & 19 & 118 & 12 \\
\hline $3 \mathrm{mg} \mathrm{ml}^{-1}$ & 119 & 17 & 126 & 16 \\
\hline $4 \mathrm{mg} \mathrm{ml}^{-1}$ & 192 & 22 & 206 & 24 \\
\hline $1 \mathrm{mg} \mathrm{ml}^{-1} 37^{\circ} \mathrm{C}$ & 126 & 18 & 124 & 14 \\
\hline $1 \mathrm{mg} \mathrm{ml}^{-1} 4^{\circ} \mathrm{C}$ & 122 & 16 & 128 & 17 \\
\hline $1 \mathrm{mg} \mathrm{ml}^{-1}$ stirred & 128 & 15 & 118 & 18 \\
\hline
\end{tabular}

*Unless indicated otherwise, all experiments were carried out at room temperature with a reaction time of $3 \mathrm{~d}$.

Means and standard deviations (SD) were based on measurements of 25 particles for each experiment.

generated in the presence of $\mathrm{rM} 179$ and $\mathrm{rP} 172$ possessed obvious internal structure (Fig. 2B,C). The materials resulting from mineralization of $\mathrm{rM} 179$ and $\mathrm{rP} 172$ were indistinguishable. The particles of $\approx 125 \mathrm{~nm}$ were composed of smaller, approximately spherical, monodisperse particles, with diameters of $\approx 20 \mathrm{~nm}$. These smaller particles appeared to be coalescing moderately, but a degree of organization within the larger particles was clearly evident (arrow, Fig. 2C), as expected from the packing of spheres of uniform size.

Small-angle X-ray scattering analysis performed on a sample of an rM179/silica composite (using $1 \mathrm{mg} \mathrm{m}^{-1}$ of rM179) resulted in a single broad ring pattern, corresponding to a d-spacing of $21.5 \mathrm{~nm}$, consistent with measurements from TEM images of the diameter of the smaller particles (Fig. 2D). Observations of samples that were allowed to react for time-periods in excess of $3 \mathrm{~d}$ showed no change in the products for up to $12 \mathrm{wk}$.

A uranyl acetate stain was applied to a sample of each material in an attempt to locate the protein within the composites. High-magnification TEM images revealed no change in the appearance of the particles in the presence of the stain (Fig. 3). This observation suggests that the protein is located within the spheres, forming

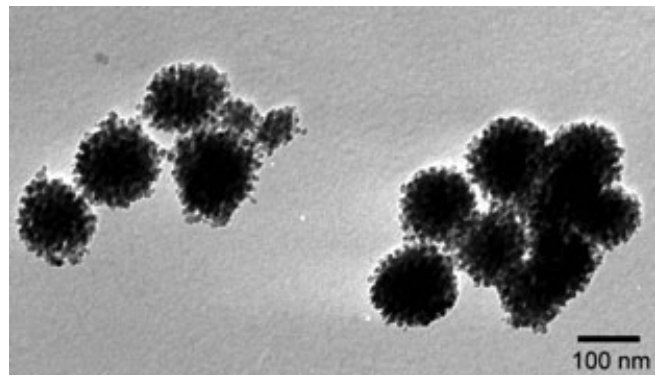

Fig. 3. High-magnification transmission electron microscopy (TEM) image of a silica/rM179 composite treated with uranyl acetate. No change was observed in the appearance of the particles in the presence of the stain, in comparison to results obtained without the stain. These results suggest that the protein is contained exclusively within the silica-coated spheres. core-shell particles, with no significant surface protein attachment or protein in the spaces between the smaller particles. Interestingly, no staining of bulk material was observed on the grids, signifying that all the available protein had been encapsulated within the spheres.

An investigation of the protein concentration dependence of the reaction revealed very little difference in products obtained from initial amelogenin concentrations of $0.1-3 \mathrm{mg} \mathrm{ml}^{-1}$ for either rM179 or $\mathrm{rP} 172$ (Table 1). Using protein concentrations in this range, large monodisperse spheres of remarkably similar mean diameters were observed using rM179 $(124 \pm 4 \mathrm{~nm})$ and rP172 $(126 \pm 7 \mathrm{~nm})$. However, composites prepared from solutions containing $4 \mathrm{mg} \mathrm{ml}^{-1}$ of either of these proteins resulted in larger particles, with mean diameters of $192 \mathrm{~nm}$ (rM179) and $206 \mathrm{~nm}$ (rP172), respectively (Table 1). The internal structure of these larger particles did not differ from that of the particles prepared using lower protein concentrations. Solubility problems hindered a study of protein concentrations of $>4 \mathrm{mg} \mathrm{ml}^{-1}$.

Temperature dependence of the particle formation was also considered. Reactions were repeated at $37^{\circ} \mathrm{C}$ and $4^{\circ} \mathrm{C}$ (Table 1). No significant differences were ascribed to products obtained at different temperatures; however, protein concentrations of $>3 \mathrm{mg} \mathrm{ml}^{-1}$ could not be investigated at $37^{\circ} \mathrm{C}$, again because of solubility problems. Mechanically stirring the reaction solutions did not affect the products (Table 1).

The recombinant rM166 and native P148 proteins were subjected to reaction conditions identical to those of the full-length mouse and pig proteins. Both rM166 and P148 lack the hydrophilic C-terminal portion of the protein sequence. Transmission electron microscopy of the silica composites prepared from both of these proteins showed large unstructured randomly shaped particles, with dimensions of $0.25-1.0 \mu \mathrm{m}$ (Fig. 4A,B). Careful examination of the thin edges of these materials at high magnification did not reveal any internal structure. No spherical particles resembling those formed from rM179 or rP172 were observed at any concentration or temperature. Control material prepared at room temperature using $2.5 \mathrm{mg} \mathrm{ml}^{-1}$ BSA was similar to those formed from rM166 and P148 (Fig. 5A).

A control sample, which contained just APTES, TEOS, and water, produced dense silica spheres (average diameter $500 \mathrm{~nm}$ ), with no evidence of internal structure (Fig. 5B).

\section{Discussion}

The present study has shown, through the use of a novel technique employing silica mineralization, that fulllength amelogenin has the potential to self-assemble to form hierarchical structures in solution and that the hydrophilic $\mathrm{C}$ terminus is essential for this to occur. Indeed, a key feature of the vast majority of biomolecules involved in the formation of biological minerals is their ability to self-assemble into organized superstructures. As noted above, it has been suggested that amelogenin forms such assemblies that help guide the organization of 

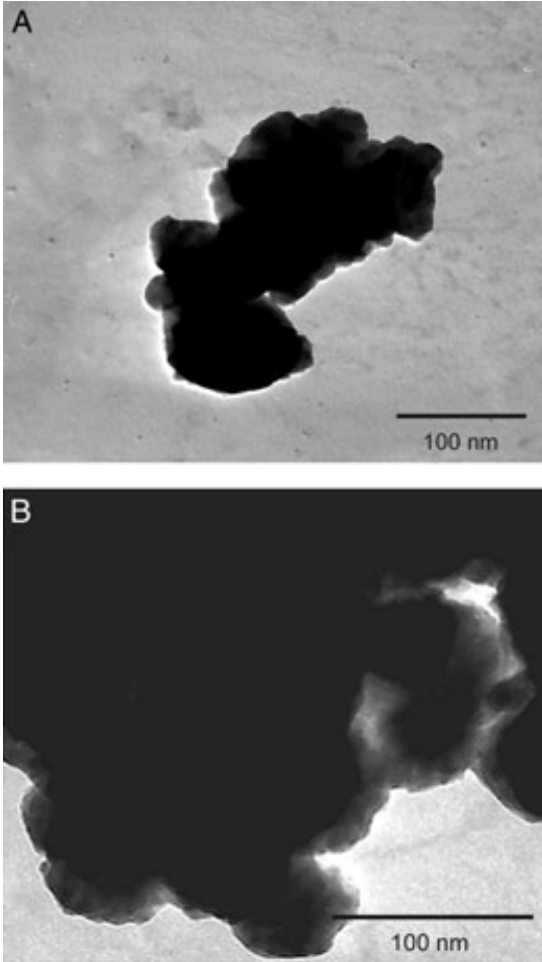

Fig. 4. Transmission electron microscopy (TEM) of silica composites prepared from both (A) rM166 and (B) P148 showed large unstructured randomly shaped particles, unlike rM179 and rP172. Both rM166 and P148 lack the hydrophilic $\mathrm{C}$ terminus found in the parent molecules (Fig. 1).

developing enamel. The present findings demonstrate that full-length amelogenins aggregate into monodisperse nanometre spheres that can pack into ordered arrays in the presence of forming amorphous silica. Such ordered arrays could provide a suitable template for controlled mineral nucleation/growth and potentially guide the organization of growing enamel crystals. The 15-20 nm particles prepared from solutions containing rM179 and rP172, visualized using the Si-mineralization technique, have similar dimensions to those reported previously for amelogenin 'nanospheres', detected by dynamic light scattering and atomic force microscopy (9,11-14). Remarkably, despite some differences in amino acid sequence of the hydrophobic portion of rM179 and rP172, these full-length proteins from two different species produced nanospheres of nearly identical size. Failure to observe the nanospheres from protein solutions containing either of the two truncated proteins (i.e. rM166 and P148) provides clear evidence that the hydrophilic region of the full-length molecule is imperative for the higher-order assembly process. Results obtained using BSA, or in the absence of protein, suggest that the structure of the full-length amelogenin specifically and uniquely drives the formation of the ordered aggregates.

The lack of dependence of nanosphere aggregate size over a wide range of protein concentrations (Table 1) is also remarkable and may be explained by considering potential interactions between the organic and inorganic components. Uniform aggregates formed from the
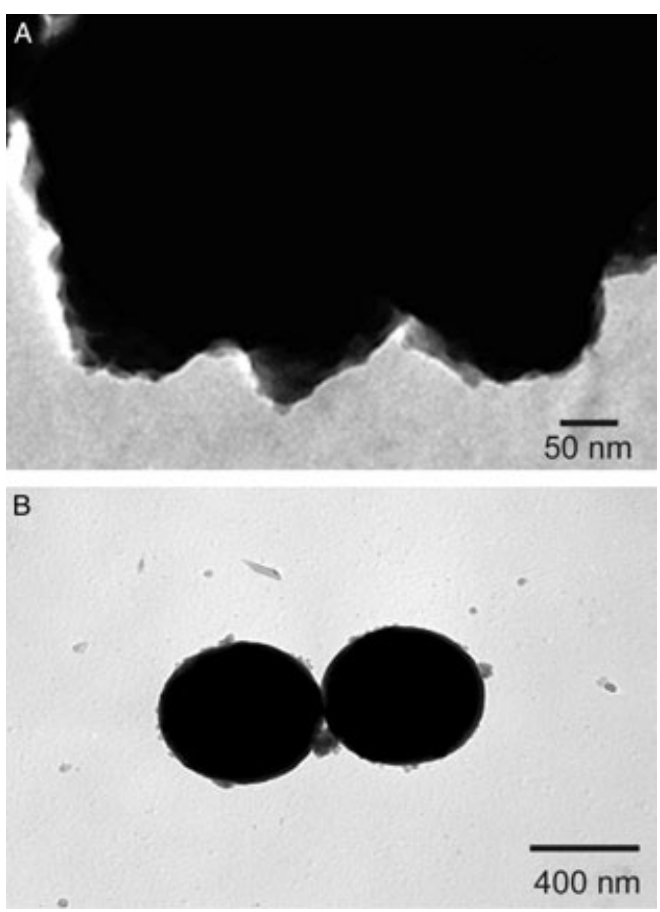

Fig. 5. (A) Transmission electron microscopy (TEM) of a silica composite prepared with control protein bovine serum albumin (BSA) (at a concentration of $2.5 \mathrm{mg} \mathrm{ml}^{-1}$ ) was similar to those formed from rM166 and P148. (B) A control sample, which contained just aminopropyltriethoxysilane (APTES), tetraethoxysilane (TEOS), and water, produced dense silica spheres (average diameter $500 \mathrm{~nm}$ ), with no evidence of internal structure.

full-length proteins may be the result of a co-operative mechanism between assembly of monomeric amelogenin molecules and formation of a silica polymer, and/or the result of the mineralization of preformed amelogenin aggregates at higher protein concentrations. However, the lack of dependence on protein concentrations (up to $3 \mathrm{mg} \mathrm{ml}^{-1}$ ) seems to suggest that a co-operative process may be involved. Aggregation of nanospheres of amelogenin to form higher-order structures in vitro has not been noted previously, possibly as a result of the low solubility of the protein, although chains of amelogenins have been observed using TEM in the presence of calcium (16) and under conditions intended to induce protein crystallization (32). The formation of chain-like structures of amelogenin was also suggested by recent findings using small-angle X-ray scattering (33). Thus, Si mineralization may have promoted the assembly of amelogenin nanosphere subunits to form the larger monodisperse Si-amelogenin composites observed under the experimental conditions used in our studies.

The Si-mineralization technique used in this study has provided unique insight into the potential ability of fulllength amelogenins to form higher-order structures, albeit in an anomalous mineralizing system. However, our present findings and suggested mechanism of composite formation are in agreement with results from our recent studies on the regulation of calcium phosphate formation by recombinant mouse amelogenins in vitro (16). 
The full-length $\mathrm{rM} 179\left(1 \mathrm{mg} \mathrm{ml}^{-1}\right)$ was found to uniquely regulate calcium phosphate formation by inducing the formation of bundles of crystals that were organized in parallel arrays. Importantly, such arrays were only evident when mineralization and self-assembly took place simultaneously. Similar results (E. Beniash, unpublished data) have been obtained recently using fulllength rP172. Furthermore, in experiments using rM166, which lacks the hydrophilic $\mathrm{C}$ terminus, organized mineral structures were not observed (16). These results are consistent with our present findings using Si mineralization, and lend support to the conclusion that fulllength amelogenins are unique in their ability to form higher order structures that can potentially regulate the organization of growing mineral crystals. In addition, both studies suggest that the protein/mineral composite structures which form are a result of co-operative interactions between the processes of organic assembly and mineralization. Our collective findings further suggest that the nature of the growing mineral phase (i.e. amorphous $\mathrm{Si}$ vs. hydroxyapatite crystals) can have a significant influence on the structure of the mineralized product. We have demonstrated that the full-length amelogenin induces organization in two different mineralizing systems, but the structures of the final products differ owing to fundamental differences in the nature of the forming mineral. However, given the observed propensity of $\mathrm{Si}$ to form an amorphous layer at organic surfaces (21-26), Si mineralization appears to result in composite structures that also reflect the organization of the organic assembly, as in the present study. Thus, this technique may provide useful information concerning the role of quaternary protein structures in other biological processes.

In conclusion, it should be added that the relatively high concentrations of amelogenin known to be present in vivo may result in gel formation, with nanospheres of amelogenin being packed closely together during the early stages of enamel development. The packing of sphere-like structures has been observed in fixed gels of amelogenin extracts in vitro (34). Forming mineral crystals may similarly influence the uniformity of structure of such a colloidal template, which may ultimately serve to guide the organization of mineral formation during the early stages of amelogenesis. Further studies will be needed to assess this latter point directly.

Acknowledgements - We gratefully acknowledge Joseph Adario and the MRSEC shared experimental facilities at MIT (supported by the NSF, award DMR98-08941) for the use of the small-angle X-ray scattering equipment, and NIDCR grant PO1-DE 13237 for support of this work. We would also like to thank Ms. Denize Kushe for her assistance with the calcium phosphate mineralization studies using rP172.

\section{References}

1. Birchall JD. The importance of the study of biominerals to materials technology. In: Mann S, WebB J, Williams RJP, eds.
Biomineralization: chemical and biochemical perspectives. New York: VCH Publishers, 1989; 491-509.

2. Avery JK, Visser RL, KNAPP DE. The pattern of the mineralization of enamel. J Dent Res 1961; 40: 1004-1019.

3. Boskey AL. Matrix proteins and mineralization: an overview. Connect Tissue Res 1996; 35: 357-363.

4. Gibson CW, Yuan Za, Hall B, Longenecker G, Chen E, Thyagarajan T, Sreenath T, Wright JT, Decker S, PidDington R, Harrison G, KulKarni AB. Amelogenin-deficient mice display an amelogenesis imperfecta phenotype. $J$ Biol Chem 2001; 276: 31871-31875.

5. Lagerstrom M, Dahl N, NaKahori $\mathrm{Y}$, Nakagome $\mathrm{Y}$, Backman B, Landegren U, Pettersson U. A deletion in the amelogenin gene (AMG) causes X-linked amelogenesis imperfecta (AIH1). Genomics 1991; 10: 971-975.

6. Aldred MJ, Crawford PJ, Roberts E, Thomas NS. Identification of a nonsense mutation in the amelogenin gene (AMELX) in a family with X-linked amelogenesis imperfecta (AIH1). Hum Genet 1992; 90: 413-416.

7. Lyngstadaas SP, Risnes S, Sproat BS, Thrane PS, Prydz HP. A synthetic, chemically modified ribozyme eliminates amelogenin, the major translation product in developing mouse enamel in vivo. EMBO J 1995; 14: 5224-5229.

8. Tan J, Leung W, Moradian-Oldak J, Zeichner-David M, FINCHAM AG. Quantitative analysis of amelogenin solubility. J Dent Res 1998; 77: 1388-1396.

9. Robinson C, Fuchs P, Weatherall JA. The appearance of developing rat incisor enamel using a freeze fracturing technique. J Crystal Growth 1981; 53: 160-165.

10. NAGASAKA S. Electron microscopy of biochemically characterized, newly secreted tooth enamel proteins. Arch Oral Biol 1994; 39: 105-110.

11. Moradian-Oldak J, Simmer JP, Lau EC, Sarte Pe, Slavkin $\mathrm{HC}$, Fincham AG. Detection of monodisperse aggregates of a recombinant amelogenin by dynamic light scattering. Biopolymers 1994; 34: 1339-1347.

12. Moradian-Oldak J, Leung W, Fincham AG. Temperature and $\mathrm{pH}$-dependent supramolecular self-assembly of amelogenin molecules: a dynamic light-scattering analysis. J Struct Biol 1998; 122: 320-327.

13. Fincham AG, Moradian-Oldak J, Simmer JP, Sarte P, Lau EC, Diekwisch T, Slavkin HC. Self-assembly of a recombinant amelogenin protein generates supramolecular structures. J Struct Biol 1994; 112: 103-109.

14. Fincham ag, Moradian-Oldak J, Diekwisch tG, Lyaruu DM, Wright JT, Bringas P Jr, SLAvkin HC. Evidence for amelogenin 'nanospheres' as functional components of secretory-stage enamel matrix. J Struct Biol 1995; 115: 5059.

15. Moradian-Oldak J, Paine ML, Lei YP, Fincham AG, Snead ML. Self-assembly properties of recombinant engineered amelogenin proteins analyzed by dynamic light scattering and atomic force microscopy. $J$ Struct Biol 2000; 131: 27-37.

16. Beniash E, Simmer JP, Margolis HC. The effect of recombinant mouse amelogenins on the formation and organization of hydroxyapatite crystals in vitro. J Struct Biol 2005; 149: 182-190.

17. Paine ML, Zhu DH, Luo W, Bringas P Jr, Goldberg M, White SN, Lei YP, Sarikaya M, Fong HK, Snead ML. Enamel biomineralization defects result from alterations to amelogenin self-assembly. J Struct Biol 2000; 132: 191-200.

18. Dunglas C, Septier D, Paine ML, Zhu DH, Snead ML, GolDBERG M. Ultrastructure of forming enamel in mouse bearing a transgene that disrupts the amelogenin self-assembly domains. Calcif Tissue Int 2002; 71: 155-166.

19. Weiner S, AdDAdi L. Design strategies in mineralized biological materials. J Mater Chem 1997; 7: 689-702.

20. Takagi T, Suzuki M, Baba T, Minegishi K, Sasaki S. Complete amino acid sequence of amelogenin in developing bovine enamel. Biochem Biophys Res Commun 1984; 121: 592-597.

21. DAvis ME. Ordered porous materials for emerging applications. Nature 2002; 417: 813-821.

22. Heuer ah, Fink DJ, laraia VJ, Arias Jl, Calvert PD, Kendall K, Messing GL, Blackwell J, Rieke PC, Thompson 
DH. Innovative materials processing strategies: a biomimetic approach. Science 1992; 255: 1098-1105.

23. Wong KKW, Douglas T, Gider S, Awschalom DD, Mann S. Biomimetic synthesis and characterization of magnetic proteins (magnetoferritin). Chem Mater 1998; 10: 279-285.

24. Archibald DD, Mann S. Template mineralization of selfassembled anisotropic lipid microstructures. Nature 1993; 364: 430-433.

25. Davis SA, Burkett SL, Mendelson NH, Mann S. Bacterial templating of ordered macrostructures in silica and silica surfactant mesophases. Nature 1997; 385: 420-423.

26. Mayes E, Vollrath F, Mann S. Fabrication of magnetic spider silk and other silk-fiber composites using inorganic nanoparticles. Adv Mater 1998; 10: 801-805.

27. Shenton W, Douglas T, Young M, Stubbs G, Mann S. Inorganic-organic nanotube composites from template mineralization of tobacco mosaic virus. Adv Mater 1999; 11: 253-256.

28. Fowler CE, Shenton W, Stubbs G, Mann S. Tobacco mosaic virus liquid crystals as templates for the interior design of silica mesophases and nanoparticles. Adv Mater 2001; 13: 1266-1269.

29. Simmer JP, lau EC, Hu CC, Aoba T, lacey M, Nelson D, Zeichner-David M, Snead ML, Slavkin HC, Fincham AG.
Isolation and characterization of a mouse amelogenin expressed in Escherichia coli. Calcif Tissue Int 1994; 54: 312 319.

30. Ryu OH, Fincham AG, Hu CC, Zhang C, Qian Q, Bartlett JD, Simmer JP. Characterization of recombinant pig enamelysin activity and cleavage of recombinant pig and mouse amelogenins. J Dent Res 1999; 78: 743-750.

31. Yamakoshi Y, Hu JC-C, Ryu O, Tanabe T, Oida S, Fukae M, SiMMER JP. A comprehensive strategy for purifying pig enamel proteins. In: Kobayshi I, Ozawa H, eds. Biomineralization (BIOM2001) formation, diversity, evolution and application. Kanagawa: Tokai University Press, 2004; 326-332.

32. Du C, Falini G, Fermanil S, Abbott C, Moradian-Oldak J. Supramolecular assembly of amelogenin nanospheres into birefringent microribbons. Science 2005; 307: 1450-1454.

33. Aichmayer B, Margolis HC, Sigel R, Yamakoshi Y, Simmer JP, FRATZL $P$. The onset of amelogenin nanosphere aggregation studied by small-angle $\mathrm{x}$-ray scattering and dynamic light scattering. J Struct Biol 2005; 151: 239-249.

34. Wen HB, Moradian-Oldak J, Leung W, Bringas P Jr, FinCHAM AG. Microstructures of an amelogenin gel matrix. J Struct Biol 1999; 126: 42-51. 